\title{
Showcase of Intraoperative 3D Imaging of the Sentinel Lymph Node in a Breast Cancer Patient using the New Freehand SPECT Technology
}

\author{
Andreas Schnelzer ${ }^{\mathrm{a}} \quad$ Alexandra Ehlerding $^{\mathrm{a}} \quad$ Christina Blümel $^{\mathrm{b}} \quad$ Asli Okur $^{\mathrm{b}}$ \\ Klemens Scheidhauer ${ }^{\mathrm{b}}$ Stefan Paepke ${ }^{\mathrm{a}}$ Marion Kiechle $^{\mathrm{a}}$ \\ ${ }^{a}$ Frauenklinik und Poliklinik, \\ ${ }^{b}$ Klinik für Nuklearmedizin, Klinikum rechts der Isar, Technische Universität München, Germany
}

\section{Keywords}

Breast cancer - Lymph node dissection .

Quality assurance $\cdot$ Sentinel lymph node

\section{Summary}

After the development of a hand-held intraoperative device for $3 D$ real-time imaging of radioactively labeled sentinel lymph nodes in the human body, we present our first experience with the newest version of the freehand single-photon emission computed tomography (SPECT) technology in the operating room. The freehand SPECT system combines a gamma probe and an optical infrared positioning system, and provides surgeons with 3D imaging including exact depth information of the radioactive target. This technology was used intraoperatively in a female breast cancer patient to localize the axillary sentinel lymph nodes. The data obtained with freehand SPECT correlate well with conventional lymphoscintigraphy and with data collected using a conventional hand-held probe. By offering fast real-time intraoperative imaging, the new freehand SPECT system might facilitate the detection and removal of the sentinel lymph node(s) in certain situations and can be used for documentation and quality assurance purposes.

\section{Introduction}

The sentinel lymph node (SLN) concept in breast cancer is an integral treatment standard in most industrialized countries [1]. However, there are several practical issues that can prevent proper identification of the sentinel node in certain

\section{Schlüsselwörter \\ Brustkrebs · Lymphknotendissektion · Qualitätskontrolle $\cdot$ Sentinellymphknoten}

\section{Zusammenfassung}

Dieser Bericht beschreibt die ersten klinischen Erfahrungen mit der neuesten Freehand-SPECT-Technologie, die zum intraoperativen Nachweis radioaktiv markierter Lymphknoten im menschlichen Körper entwickelt wurde. Die technische Grundlage basiert auf der Kombination einer konventionellen Gammasonde mit einem optischen Infrarot-Positionierungssystem. Der Operateur erhält eine räumliche Darstellung der Radioaktivität einschließlich der exakten Tiefenangabe im menschlichen Körper. Bei einer Mammakarzinompatientin wurde das System zum Auffinden des axillären Sentinellymphknotens verwendet. Die erhobenen Messwerte korrelieren sowohl mit den Ergebnissen einer konventionellen Lymphszintigraphie als auch mit den intraoperativen Messungen der mobilen Gammasonde. Die neue Freehand-SPECT-Technologie hat das Potential, dem Operateur durch die räumliche Echtzeitdarstellung der Radioaktivität das Auffinden und Entfernen des Sentinellymphknotens in bestimmten Situationen zu erleichtern und kann zu Zwecken der Dokumentation und Qualitätssicherung dienen.

clinical scenarios. Moreover, the criteria for defining sentinel nodes have recently been questioned [2], including the value of dynamic information [3] or the value of preoperative lymphoscintigraphy [4]. Despite improvements with the introduction of single-photon emission computed tomography/ computed tomography (SPECT/CT) [5], the problems behind

\section{KARGER \\ Fax +497614520714 \\ Information@Karger.de}

www.karger.com (c) 2012 S. Karger GmbH, Freiburg

$1661-3791 / 12 / 0076-0484 \$ 38.00 / 0$

Accessible online at:

www.karger.com/brc 
some of these questions are based on the impracticability to utilize the information gained from preoperative imaging during the operative procedure of SNL biopsy (SLNB) using only a hand-held gamma probe. Intraoperative lymphoscintigraphy may help to solve at least some of these problems and shed light on these controversies.

The freehand SPECT technology was introduced by Wendler et al. in 2010 within a preoperative setup [6]. This report presents its initial evaluation in the operating room in an SLNB procedure for breast cancer.

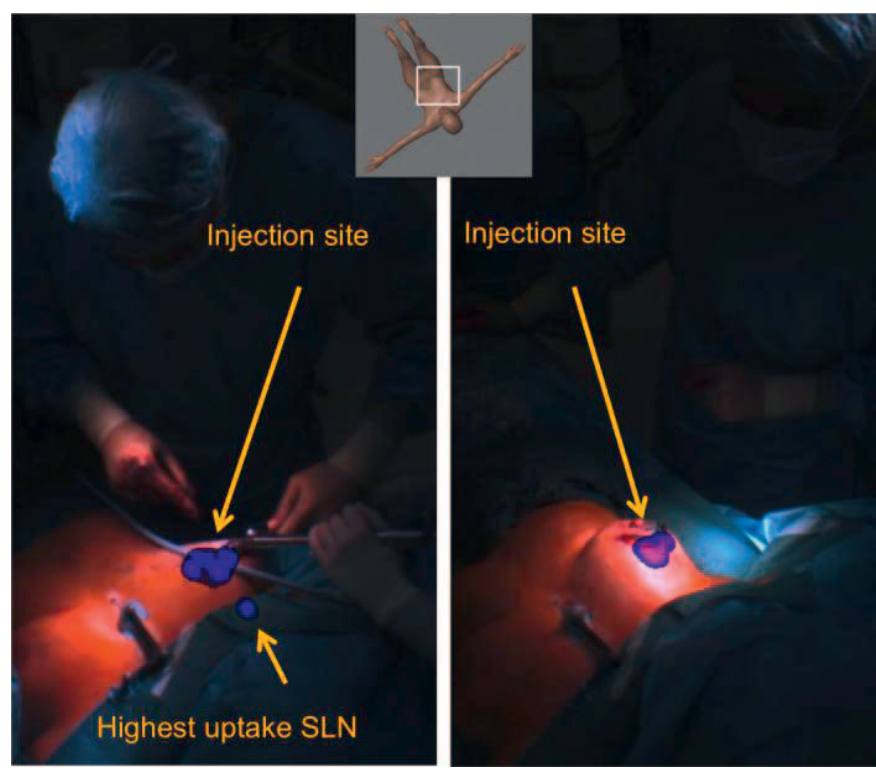

Fig. 1. Overlay picture of radioactivity data obtained with an intraoperative freehand single-photon emission computed tomography (SPECT) scan in projection on the live video of the patient showing the anatomic position of the axillary lymph node with the highest uptake (left). A second freehand SPECT scan was conducted after the surgical removal of the sentinel lymph node (SLN), which confirmed that there was no residual radioactive activity in the axilla (right).
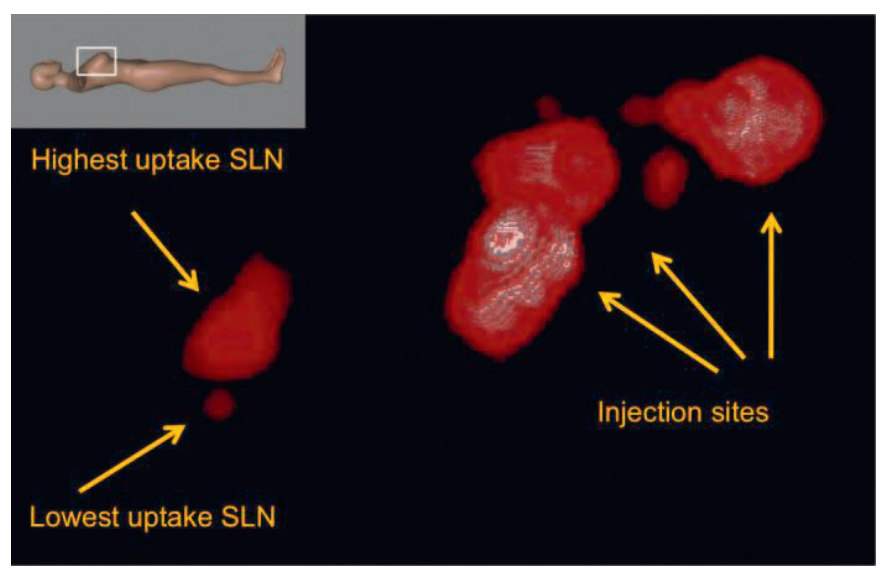

Fig. 2. Zoom on the freehand SPECT image in lateral view showing higher uptake and lower uptake lymph nodes before incision. This visualization was obtained using the pre-incision acquisition data as well as other visualization parameters so that the lower uptake lymph node could be clearly separated from the higher uptake lymph node.

\section{Methods}

To generate freehand SPECT images, the position and orientation of a hand-held gamma probe is acquired simultaneously with its read-out using an optical infrared positioning system. After obtaining synchronized readings from a patient scan containing the region of interest (e.g. the axillary region), the information is used to reconstruct $3 \mathrm{D}$ tomographic nuclear images (equivalent to SPECT) using ad hoc models and iterative reconstruction algorithms. The scan of the region of interest is performed by the surgeon by moving the gamma probe over the skin of the breast and axillary region. The surgeon can visualize the radioactivity as an overlay view in the real-time video provided by a camera mounted over the operation table and pointing at the patient (figs. 1 and 2).

This technology was used intraoperatively in a female breast cancer patient to localize the axillary sentinel lymph nodes. A 39-year-old female patient had undergone core needle biopsy to confirm invasive breast cancer, and was scheduled for axillary SLNB. She underwent dynamic lymphatic mapping (2.9 mCi/107 MBq Tc-99m nanocoll, 2 min planar, frontal and lateral acquisitions with and without lead shielding). This study has been approved by the local Ethics Committee at the Medical Faculty of Technische Universität München (Technical University Munich).

\section{Results}

Preoperative stationary SPECT images in our patient showed one SLN with high uptake and a secondary node with low uptake (fig. 3). At $16 \mathrm{~h}$ after injection, freehand SPECT images (declipseSPECT ${ }^{\circledR}$, SurgicEye, Munich, Germany) were acquired immediately before skin incision with the patient already being positioned on the operation table. Nonradioactive blue dye was injected $5 \mathrm{~min}$ before the freehand SPECT scan as advised in the standard procedure.

Intraoperative freehand SPECT showed 2 radioactive lymph nodes in the axillary region with significantly different uptake, matching with preoperative images (figs. 1 and 2). The system showed the depth information (18 and $20 \mathrm{~mm}$ ) from skin and the direction of the lymph node in relation to the probe tip. This information was used to minimally dissect the axillary tissue and extract the SLNs rapidly without major exploration of the axilla. The depth localization of the identified radioactive SLN was confirmed intraoperatively with the regular gamma probe and blue dye as the existing reference. The additional time required for the acquisition of freehand SPECT scans was approximately $5 \mathrm{~min}$.

A second freehand SPECT scan was performed after the removal of the SLN (additional duration of the procedure, $5 \mathrm{~min}$ ). Post-excisional images showed no residual radioactive activity in the axilla.

\section{Discussion}

The availability of intraoperative nuclear imaging has opened new options in radio-guided surgery [7, 8]. A major advantage of the newly developed technique of freehand SPECT is that real-time imaging can be performed in the operating room and - upon demand - at any time during surgery. For the first 
time surgeons can intraoperatively use 3D stereotactic imaging of radioactive lymph nodes in breast cancer patients. The feasibility has already been evaluated in breast cancer patients with an early prototype of the system [6], showing the potential of completely omitting preoperative scintigraphy. Experienced surgeons in our department have evaluated the most recent hardware version named declipseSPECT. The main breakthrough is the visual combination of the depth information for the sentinel node measured from the skin edge and the relation of the lateral margins of the sentinel node to the gamma probe. The more precisely a surgeon can localize the sentinel node, the less dissection of axillary tissue is probably necessary. Extensive axillary dissection can lead to lymphedema of the arm and subsequent morbidity. The freehand SPECT technology cannot yet be considered a routine technique as it is still necessary to first demonstrate advantages and disadvantages in prospective clinical trials. Considering the growing issue of quality control and for quality assurance purposes, the system can already be used to detect whether all SLNs have been successfully removed from the axilla. This cannot be documented digitally with conventional hand-held gamma probes, and is dependent on the personal judgment and documentation of the handling surgeons. The availability of 3D images also allows navigation for real-time localization in deeper lying structures. The intuitive fusion of optical and nuclear images opens further perspectives in many other clinical scenarios, helping to justify the cost of the onetime investment for the technical equipment. Each department finally has to decide about the individual need for the technique in a cost-benefit calculation; the advantages might pay off in different ways and the running costs are low.

The freehand SPECT also provides a new scientific potential for resolving the controversies in the integral SLN concept mentioned above. Controlled studies using intraoperative 3D imaging could help to clarify many of the discussed issues, including the role of lymphatic uptake on selecting the nodes for surgical resection [2]. Also, the option of being able to transfer dynamic information from preoperative imaging into
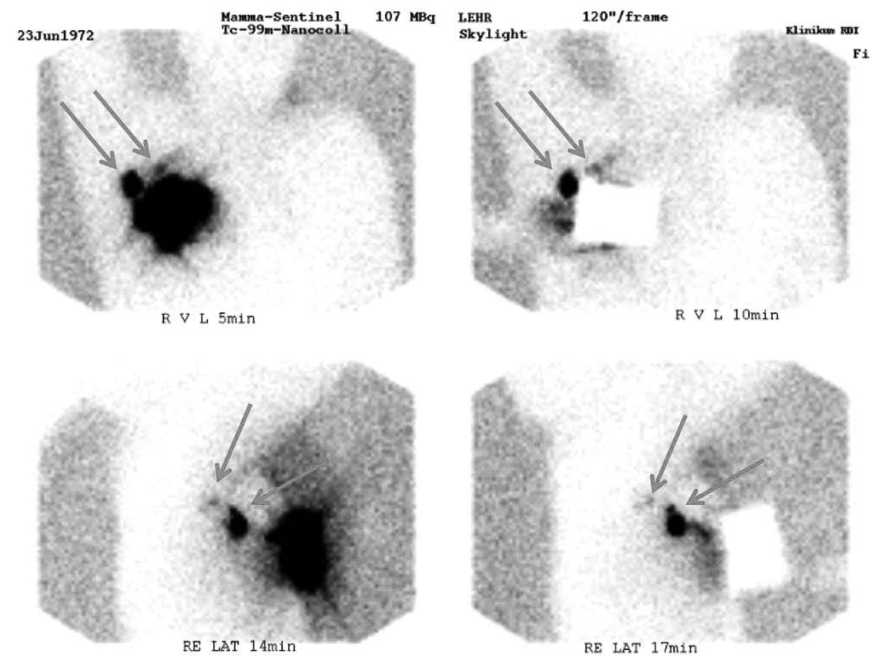

Fig. 3. Preoperative lymphoscintigraphy showing 2 lymph nodes with considerably different uptake (arrows) 5 min post injection (upper left). For better localization, the injection spot was covered with a lead plate before taking the second frontal image (upper right). Lateral images (acquired with and without the lead plate 14 and 17 min after injection) show the depth of the nodes more clearly (lower panel).

the operating room [3] or even the possibility of skipping preoperative imaging [4] brings additional advantages over the standard procedure.

While helping to clarify some of these issues, the SLN procedure in breast cancer also offers a simple framework for testing these new technologies and evaluating potential advantages and disadvantages. This is particularly interesting when considering more complex applications like SLNB procedures in the deep abdomen (e.g. in cancer of the cervix, vulva $[9,10]$ or prostate) or procedures such as radio-guided occult lesion localization, where depth and imaging information can have a major impact on the overall performance of the procedure.

\section{Disclosure Statement}

The authors declare that they have no conflicts of interest to declare.

\section{References}

1 Lyman GH, Giuliano AE, Somerfield MR, Benson AB 3rd, Bodurka DC, Burstein HJ Cochran AJ, Cody HS 3rd, Edge SB, Galper S, Hayman JA, Kim TY, Perkins CL, Podoloff DA, Sivasubramaniam VH, Turner RR, Wahl R, Weaver DL, Wolff AC, Winer EP: American Society of Clinical Oncology guideline recommendations for sentinel lymph node biopsy in early-stage breast cancer. J Clin Oncol 2005;23:7703-7720.

$\checkmark 2$ Schuman S, Walker G, Avisar E: Processing sentinel nodes: When and how many? Arch Surg 2011;146:389-393.

>3 Doting MH, Stiekema HM, de Vries J, Lemstra C, Hoekstra HJ, Vrieling M, Rietman L, Jager PL: Immediate dynamic lymphoscintigraphy delivers no additional value to lymphoscintigraphy $3 \mathrm{hr}$ after tracer injection in sentinel lymph node biopsy in breast cancer patients. J Surg Oncol 2007;95:469-475.
4 Sadeghi R, Forghani MN, Memar B, Abdollahi A, Zakavi SR, Mashhadi MT, Raziee HR, Tavassoli A, Kakhki VR: Comparison of pre-operative lymphoscintigraphy with inter-operative gamma probe and dye technique regarding the number of detected sentinel lymph nodes. Hell J Nucl Med 2009;12:30-32.

5 Husarik DB, Steinert HC: Single-photon emission computed tomography/computed tomography for sentinel node mapping in breast cancer. Semin Nucl Med 2007;37:29-33.

6 Wendler T, Herrmann K, Schnelzer A, Lasser T, Traub J, Kutter O, Ehlerding A, Scheidhauer K, Schuster T, Kiechle M, Schwaiger M, Navab N, Ziegler SI, Buck AK: First demonstration of 3-D lymphatic mapping in breast cancer using freehand SPECT. Eur J Nucl Med Mol Imaging 2010;37:1452-1461.
7 Valdés Olmos RA, Vidal Sicart S, Nieweg OE: SPECT-CT and real-time intraoperative imaging: New tools for sentinel node localisation and radioguided surgery? Eur J Nucl Med Mol Imaging 2009;36:1-5.

8 Naji S, Tadros A, Traub J, Healy C: Case report: Improving the speed and accuracy of melanoma sentinel node biopsy with 3D intra-operative imaging. J Plast Reconstr Aesthet Surg 2011;64:1712-1715.

$\checkmark 9$ Kim W, Menda Y, Willis J, Bartel TB, Graham MM: Use of lymphoscintigraphy with SPECT/CT for sentinel node localization in a case of vaginal melanoma. Clin Nucl Med 2006;31:201-202.

10. Kobayashi K, Ramirez PT, Kim EE, Levenback CF, Rohren EM, Frumovitz M, Mar MV, Gayed IW Sentinel node mapping in vulvovaginal melanoma using SPECT/CT lymphoscintigraphy. Clin Nucl Med 2009;34:859-861. 